\title{
ASSESSMENT OF TRAFFIC LOAD EVENTS AND STRUCTURAL EFFECTS ON ROAD BRIDGES BASED ON STRAIN MEASUREMENTS
}

\author{
Helder SOUSA ${ }^{\mathrm{a}}$, Bruno J. A. COSTA ${ }^{\mathrm{a}}$, António Abel HENRIQUES ${ }^{\mathrm{b}}$, João BENTO ${ }^{\mathrm{b}}$, \\ Joaquim A. FIGUEIRAS ${ }^{\mathrm{a}}$ \\ ${ }^{a}$ LABEST, Faculdade de Engenharia, Universidade do Porto, 4200-465 Porto, Portugal \\ ${ }^{b}$ Efacec Capital SA, Parque Empresarial da Arroteia, 4466-952 S. Mamede de Infesta, Portugal
}

Received 12 Sep 2012; accepted 22 May 2013

\begin{abstract}
Several technical and scientific publications have been made available focussing on Bridge Weight-in-Motion (BWIM) concerning railway bridges. On the contrary, BWIM analysis on road bridges are more scarce and therefore, this work intends to provide a contribution by presenting the BWIM analysis performed on two major road bridges in Portugal - Lezíria Bridge and Pinhão Bridge. These bridges are equipped with electric and optical strain gauges, acquisition systems with features that allow high sampling rates. Based on the collected data and focussing on the bridges' lifetime, a probabilistic approach to quantify extreme traffic loads was implemented using extreme distribution functions. The bridges' behaviour to these extreme traffic loads is numerically evaluated and a comparison with the alarm levels established by the bridge designers is performed. Although the bridge's safety is not compromised, it was concluded that the representativeness of the observation period is a critical issue and the analysis of this kind of results must be carefully considered. A comprehensive discussion about this matter is carried out at the end of this work.
\end{abstract}

Keywords: road bridges, structural monitoring, bridge-weight-in-motion, distribution functions, assessment, structural safety.

\section{Introduction}

Civil infrastructure projects are often large-scale investments undertaken to improve the quality of life for entire communities. Nonetheless, after the first investment on their construction, the follow-up along the life cycle becomes mandatory. In recent years, there has been an increasing interest in structural monitoring within the scientific and technical communities. Moreover, the development of Bridge Health Monitoring Systems (BHMS) and their application has spread worldwide. Although initially the attention was addressed to sensor applications, nowadays it is also extended to the practical implications related to the acquisition, collection and processing of data (Van der Auweraer, Peeters 2003). Currently, it is possible to remotely monitor highly instrumented structures, with a high degree of automation. In fact, the most recent solutions are sufficiently versatile to carry out remote surveillance tasks with moderate costs (Bergmeister, Santa 2001; Chang et al. 2009).

Depending on the selected equipment and sensors, the current systems for the monitoring of civil infrastructures such as bridges, allow for data acquisition with sampling rates up to $1 \mathrm{kHz}$. Furthermore, in addition to the common use of these systems, i.e. for the assessment of the structural integrity, they can actually be used to characterise the crossing traffic, if properly designed for that. Indeed, if bridges are equipped with suitable monitoring systems, they can act as a weighting device as long as linear elastic behaviour is assured and consequently traffic parameters may be quantified Bridge-Weigh-In-Motion (BWIM) - (Karoumi et al. 2005). One of the first works related to the identification of traffic loads on bridges based on strain measurements was presented by Moses (1979). The Weight-In-Motion analysis is an inverse-type problem where the structural response (bending moment, for instance) is measured and the traffic load causing it is unknown. Good correlation between gross load and peak strains has been shown in previous analyses (Moses 1979; Liljencrantz et al. 2007; Liljencrantz, Karoumi 2009). This fact may definitely contribute to improve the knowledge of real traffic loads on bridges. Moreover, an approach that takes into account the traffic loads and volume statistics from a specific bridge site provides a more accurate representation of the actual loading conditions and consequently, funds might be saved by avoiding unnecessary rehabilitation and replacement procedures (Getachew, Obrien 2007). Several technical and scientific publications have been 
made available focussing on BWIM applied to railway bridges, either metallic or concrete structures. However, the same number of publications is not attained for the case of road bridges yet. The main reasons are: (1) vehicles, hence the loads, travel along a well-defined path on railway lines; (2) railway vehicles always have two wheels per axle; and probably the most important; (3) track rails are excellent candidates to host instrumentation systems required to collect reliable data. In this context, studies on road bridges equipped with appropriate monitoring systems are crucial in order to collect data to improve the knowledge of real traffic events that take place on this type of bridge, as well as providing a more detailed evaluation of effective safety levels.

In this context, this work reports a comprehensive analysis on the quantification of traffic loads and their structural effects on two major road bridges in Portugal Lezíria Bridge and Pinhão Bridge - based on monitoring data. Moreover, it aims to contribute for the setting of more reliable structural safety levels.

Firstly, the article focuses on: (1) the monitoring systems installed in both structures and the Finite Element (FE) models specifically developed to validate the monitoring data, and (2) the probabilistic approach based on extreme distribution functions, namely the Weibull distribution, in order to get a reliable representation of the real traffic loads. Data processing is crucial for large amounts of data and therefore, the authors used a piece of software to support the management, treatment and analysis of data MENSUSMONITOR (Sousa et al. 2009).

Secondly, a brief description of the selected sensors for this study is made, followed by the presentation of the main results. Taking as reference the bridges' lifetime, characteristic loads are calculated based on the fitted Weibull distribution. These loads are then used to numerically evaluate the bridges' response under extreme load scenarios and compared with the alarm levels established by the bridges' designers.

Finally, a comparative analysis is presented in order to scrutinise the different results obtained for both bridges. The main conclusions are drawn at the end of this work.

\section{Bridges - case studies}

The research presented in this manuscript is based on the following two road bridges: (a) Pinhão Bridge and (b) Lezíria Bridge (Fig. 1), which cross the two major rivers of Portugal, the River Douro and River Tagus respectively. Remote, automatic and programmable monitoring systems were installed in these structures by LABEST-FEUP. The differences in age, structural solution and traffic features are stressed in this section.

\subsection{Pinhão Bridge}

This structure comprises three $68.95 \mathrm{~m}$ long simply supported steel spans and is a crucial part of the national road network infrastructure. It enables the crossing of the River Douro in the DOC vineyard region, where the

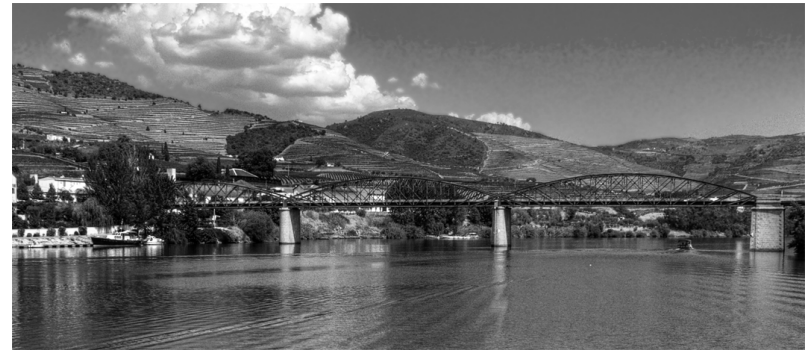

a) Pinhão Bridge

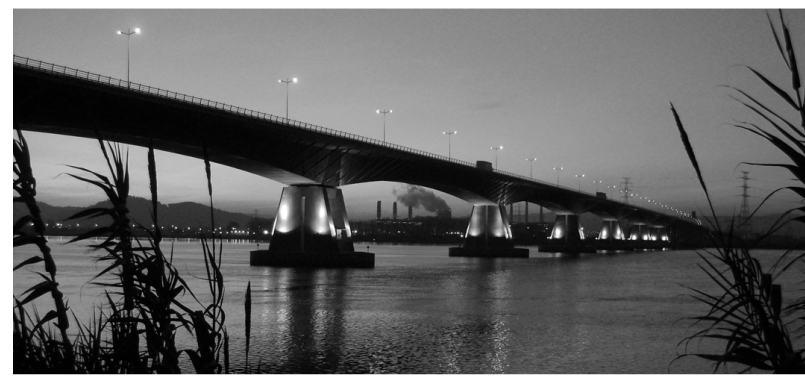

b) Lezírie Bridge (main structure)

Fig. 1. Road bridges in Portugal

famous Porto wine is produced. After the tragic collapse of an older bridge crossing the same river, which occurred in 2001 (Jowell 2001), the authorities held a thorough inspection as well as a viability study of Pinhão Bridge that led to its strengthening and rehabilitation.

A sensing network of 32 strain gauges, 8 temperature sensors, 6 displacement transducers and 2 tiltmeters composes the long-term observation system installed in this bridge (Fig. 2a and b). Additionally, two acquisition units acquire the sensors' measurements (Fig. 2c) at a sampling rates of up to $100 \mathrm{~Hz}$, which enables to record the structure dynamic response (Costa et al. 2009).

Pinhão Bridge was included in this study for two main reasons: (1) after the structure rehabilitation, it was important to assess conformance with the posted speed and load limits; (2) the existence of a single lane along the bridge deck, which imposes alternate traffic, was taken into account in the design of the monitoring system to improve the traffic characterisation.

Based on FE analysis, a numerical model was developed to appraise the bridge behaviour. The webs of the transverse and longitudinal I-beams were simulated by shell elements and the flanges modelled with bar elements, in order to capture simultaneously the torsion, shear and bending deformations. The concrete deck slab was also modelled with shell elements and connected to the top of the beams grid through stiff bars, in order to guarantee shear connection between them. All the remaining structural elements were modelled with bars and a rigid joint behaviour was assumed in their connections.

\subsection{Lezíria Bridge}

Lezíria Bridge is part of the A10 motorway in Portugal and its main structure has a total length of $970 \mathrm{~m}$, with eight spans of $95+127+133+4 \times 130+95$ m length, 


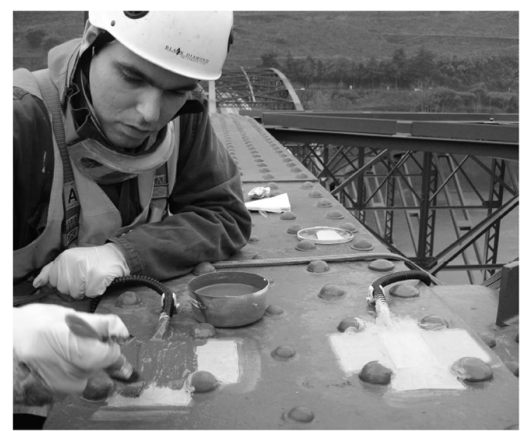

a) sensors' installation

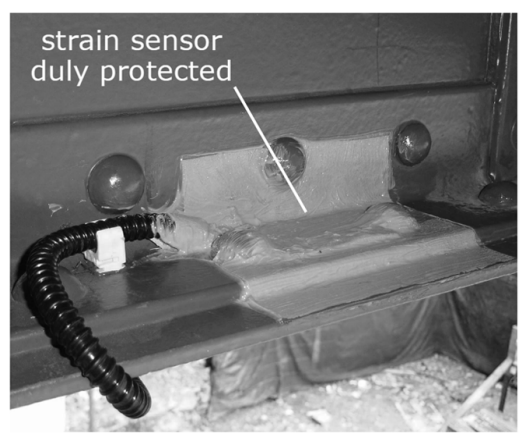

b) sensor SG-13B

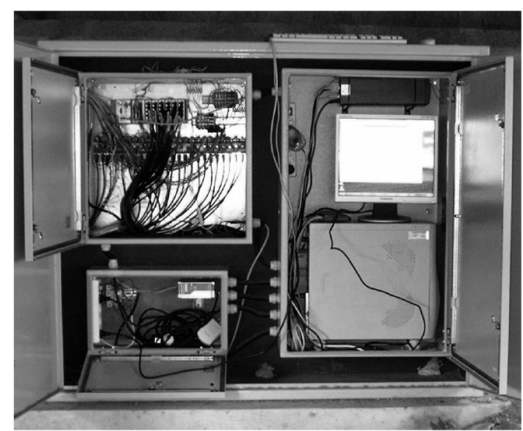

c) local observation station

Fig. 2. Monitoring system of Pinhão Bridge

respectively, and seven piers supported by pilecaps over the riverbed. The bridge deck is a box girder with variable inertia - approximately $30.00 \mathrm{~m}$ wide with a height ranging from $4.00 \mathrm{~m}$ to $8.00 \mathrm{~m}$. The box girder core was segmentally built using a movable scaffolding system, while the side cantilevers were later constructed with specific movable scaffolding and supported on metallic struts fixed on the bottom slab of the box girder. The concrete piers are supported by pilecaps and are set by four walls of constant thickness and variable width.

The bridge has an integrated monitoring system devoted to its management and surveillance. Several cross sections are instrumented with embedded and external sensors. The installed sensors measure a set of static, dynamic and durability quantities. The sensors selected for this analysis are part of the 30 fibre optic strain gauges (Fig. 3a) specifically developed for this bridge (Rodrigues et al. 2007; Sousa et al. 2011). They were installed in 15 cross sections along the bridge deck, seven of which are positioned near the support piers, and the remaining eight located at the middle of the spans. In each instrumented section, two fibre optic strain gauges were installed (Fig. 3b), each one in the bottom and top slabs of the box girder, both aligned with the vertical symmetry axis of the section and the longitudinal axis of the bridge. A local communication network enable the assembly of all records, acquired by the different Acquisition Nodes (AN), in a single location so called as Central Acquisition Node (CAN) (Fig. 3c). Lezíria Bridge is part of the motorway network operated by BRISA and therefore included in its sophisticated communication network that covers the entire motorway system. A link established between the local communication network and BRISA's communication networks enables the remote access to the bridge monitoring system (Sousa et al. 2011).

The capability of the implemented monitoring system to acquire strain measurements at a high rate level enables the detection of traffic events, which makes this bridge a suitable candidate for this analysis.

As in the case of Pinhão Bridge, a FE analysis was developed for Lezíria Bridge. Regarding the structural assessment and support the structure surveillance, this analysis considered the effective chronological erection timetable, the real mechanical properties of the applied concrete and steel and the prestressing forces. A thorough scanning of the structure geometry was carried out based on the bridge project, namely the final drawings. A two-dimensional

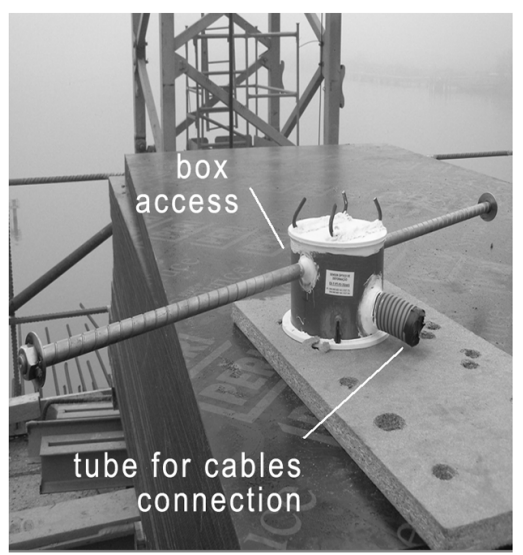

a) fibre optic strain gauge

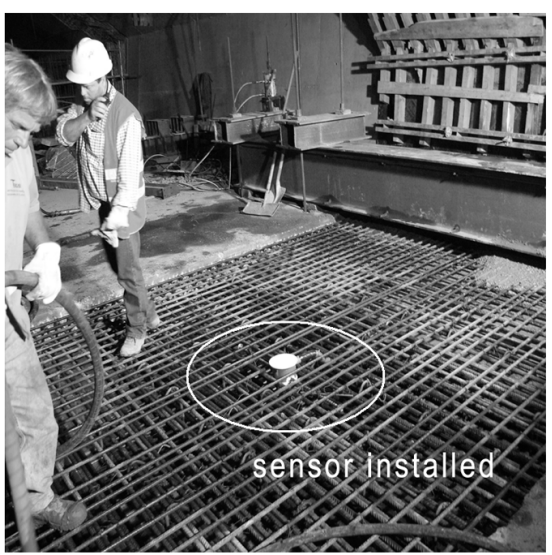

b) cross section at mid-span

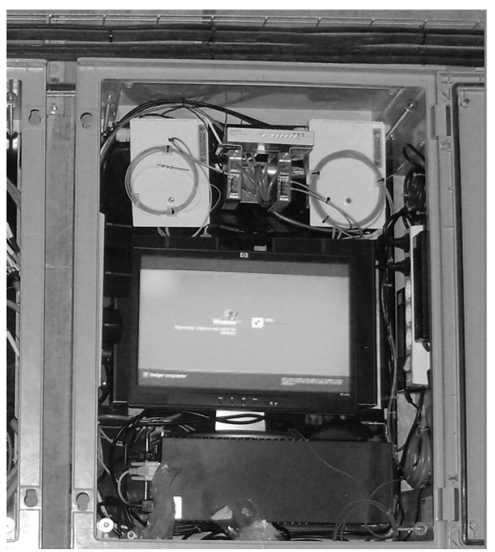

c) acquisition node

Fig. 3. Monitoring system of Lezíria Bridge 
model was built with beam elements to simulate the concrete elements of the bridge, which is an acceptable approach to analyse the overall bridge behaviour.

Both reinforcement steel and prestressing cables embedded in the concrete were modelled as reinforcing elements attached to the respective beam elements. In fact, these elements have a stiffness contribution for the structural response and a restriction effect on concrete deformations due to shrinkage and creep, which are always important to consider for long-term analyses.

The external prestressing cables were simulated with truss elements. Besides the mechanical properties, the time-dependent properties of concrete and steel were considered, namely the concrete hardening, shrinkage and creep as well as the relaxation of prestressing steel.

\section{Characterisation of the traffic loads and their structural effects based on sensor measurements}

Aiming at the characterisation of traffic loads based on collected strain time series, a set of four main steps were established and sequentially followed, starting from sensor measurements up to the desired traffic parameters, namely: (1) sensors selection and pre-treatment of the corresponding time series; (2) recognition of the local peaks contained within the time series, and based on this information the evaluation of speed and travelling directions; (3) calculation of traffic loads through correlation with the identified peaks; (4) probabilistic extrapolation of higher loads and assessment of their structural effects.

\subsection{Sensors selection and pre-treatment of data}

For the identification of traffic load events, a high correlation with the sensor readings is required, i.e. most of the local peaks contained within the sensor reading must correspond to traffic events. In general, strain measurements exhibit good properties due to their sensitivity to bending moments, and therefore, to vehicles' crossing. In fact, several authors have used this kind of measurement for the identification of traffic events (Moses 1979; Liljencrantz et al. 2007; Liljencrantz, Karoumi 2009). The influence line concept is a reliable method for the selection of the best sensors from all available (Moses 1979; Liljencrantz et al. 2007; Liljencrantz, Karoumi 2009). This can be evaluated through load tests and/or FE analyses, where higher amplitudes on the influence line reveals higher sensitivity to traffic loads. In addition, the influence of sensor's noise is reduced with this strategy, because its relative weight decreases as the maximum value of the influence line increases. After checking all available sensors, in general for the present purpose, two sensors were enough.

Before any calculus, time series are properly pretreated. In a first step, trends contained in the time series, commonly due to environmental effects, are removed and afterwards, treated with a Savitzky-Golay modified filter capable of smoothing the stationary time periods of the signal without significantly reducing the peak values (Savitzky 1964; Sousa et al. 2006).

\subsection{Local peaks recognition in the time-series}

The identification of local peaks is performed by setting a threshold value $Y_{0}$. In a first step, all measurements lower than $Y_{0}$ are eliminated and a new time series is created with a set of time gaps. In fact, these time gaps are the key indicator to identify the local peaks. Methodically, if the time difference between two consecutive samples of this new time series is different from the signal period, this means that a new event is found and a new local peak exists. The maximum value is searched, while the elapsed time between two consecutive samples remains equal to the signal period. When the while criterion fails, the searching process stops and the identified local peaks (value and time of occurrence) are stored. Afterwards, a new search begins and the process is repeated until the end of the time series.

The value of the threshold $Y_{0}$ has to be optimised in order to maximise the number of identified peaks. If the raw time series is scrutinised, it is easy to conclude that the noise amplitude is the main criterion to quantify $Y_{0}$. The sensors' accuracy, the cables' length, the characteristics of the acquisition systems and the vibration of the structure largely influences the noise amplitude, which in fact may lead to a significant reduction on the number of identified peaks if no pre-treatment is considered.

In addition, other types of information might be achieved, namely the speed and travelling direction, if two local peaks from two different measurements are taken into consideration. The ratio between the spacing distance of the sensors, $\Delta x$, and the elapsed time between peaks, $\Delta t$, provides a reasonable estimation of the average speed, $v_{\text {avg }}$, while the ratio sign denounces the travelling direction.

\subsection{Determination of the load level}

Studies concerning load models for bridge assessment carried out by Getachew and Obrien (2007) and Cremona (2001) showed that the prevailing heavy load vehicles correspond to five-axle trucks. The trucks used for the load tests in both bridges have three to five axles in correspondence with vehicles' lengths from $5 \mathrm{~m}$ to $12 \mathrm{~m}$ (Rodrigues et al. 2007; Costa et al. 2008). Therefore, these values are relatively small if compared to the span lengths of Lezíria and Pinhão bridges (see Sections 2.1 and 2.2). Moreover, as presented later, the readings of the strain gauges exhibit a single peak for each detected traffic event. This means that individual load axles are not distinguishable and the vehicle weight might be considered as a single load. Hence, the load level related with a traffic event detected from a strain gauge measurement can be achieved through Eqn (1), where $P_{i}$ and $\varepsilon_{i, p e a k}$ are the estimated load and the measured strain peak at instant $t$, respectively, while $k_{0}, k_{1}$ and $k_{2}(t)$ are constants that depend on the problem under analysis and has the following definitions:

\subsubsection{Sensitivity parameter $-k_{0}$}

A strain gauge measurement is a record of an electric or optical signal. An accurate calibration must be made in 


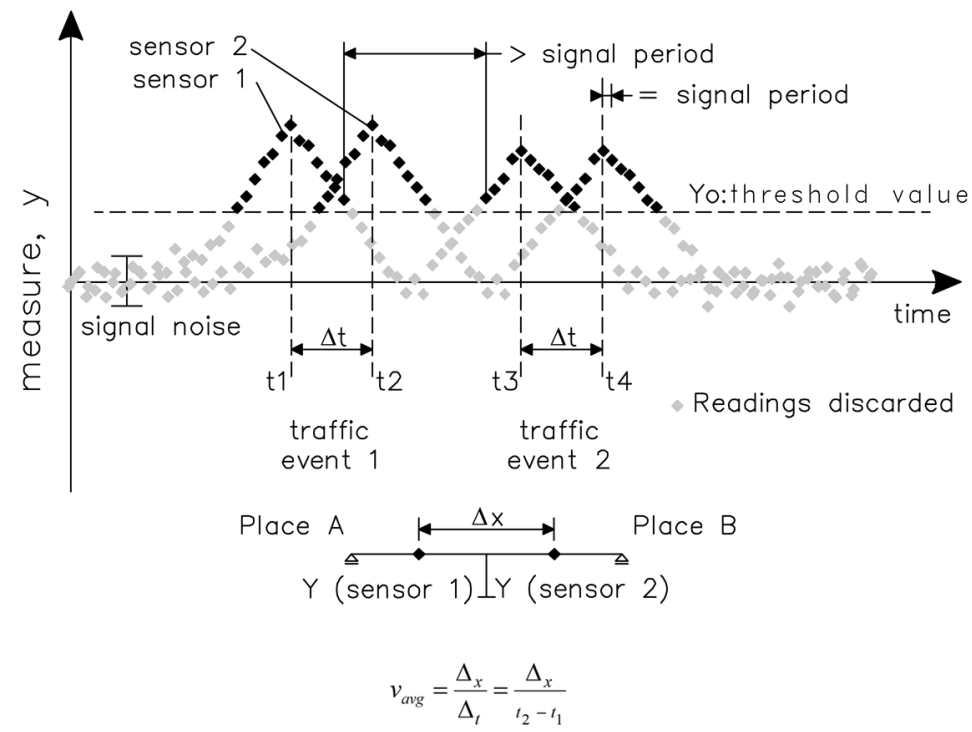

Fig. 4. Identification of local peaks and time gaps of two sensors readings

order to improve the correlation accuracy between the collected signal and the actual deformation experienced by the bridge. Although the sensors' manufacturer usually provides this information, when a strain gauge is installed in a bridge additional uncertainties might exist related to its alignment and position. Therefore, and for this work, the sensors' calibration is indirectly performed through the sensitivity parameter, $k_{0}$, which establishes the relation between the sensor measurement and the applied load for a baseline condition. The most suitable way to set the value for $k_{0}$ is through field testing, in which the loads magnitude and their positioning are perfectly known and controlled. A direct correlation can be established between the strain gauge measurement, $\varepsilon_{r e f}$, and the load, $P_{r e f}$, as shown in Eqn (2). In order to guarantee a high confidence level in the estimated values, their validation through $\mathrm{FE}$ analysis was also carried out.

It should be noted that the loads applied during load tests are usually centred with the longitudinal axis of the bridge, which is not the current situation under operational conditions. Despite this fact, this methodology focuses on long span bridges, for which loads are mainly carried out through bending and consequently, torsion effects might be considered negligible in the sensors' readings.

\subsubsection{Load length correction $-k_{1}$}

Currently, load tests on bridges comprise a specific number of trucks that are grouped and positioned according to different configurations, in order to evaluate, in a comprehensive mode, the structural behaviour. Often, those loading schemes are composed by two, three or more trucks in a line formation. However, these configurations are not representative of the ordinary daily traffic, because they correspond to frequent or characteristic load combinations. In other words, most of the daily traffic loads are related to the passages of one vehicle only and in this context, a correction is required in order to take into account the different loading lengths used in the load tests and the characteristics of the ordinary daily traffic. This correction can be supported on the influence lines of the strain gauges selected for this analysis. Therefore, a coefficient $k_{1}$ is set by means of a ratio between the strain, $\varepsilon$, produced by a point load of value ' $Q$ ' and the strain, $\varepsilon_{r e f}$, obtained with the same total load 'Q' but uniformly distributed along a specific length, as expressed in Eqn (3).

\subsubsection{Modulus of elasticity correction $-k_{2}(t)$}

Concrete exhibits viscous-elastic properties and therefore, its modulus of elasticity is time-dependent. This means that, for the same load level, different deformations are expected for different ages. Bias due to this fact can be mitigated, if a correction factor $k_{2}(t)$ is considered by expressing the ratio between the modulus of elasticity at the observation period, $E_{c}(t)$ and the modulus of elasticity at the age of the load test (baseline condition), $E_{c, r e f}$, as expressed in Eqn (4):

$$
\begin{aligned}
& P_{i}(t)=k_{2}(t) \cdot k_{0} \cdot \varepsilon_{i, p e a k}(t) ; \\
& \left\{\begin{array}{l}
k_{0}=\mathrm{P}_{r e f} / \varepsilon_{r e f} ; \\
k_{1}=\varepsilon / \varepsilon_{r e f} ; \\
k_{2}(t)=E_{c, r e f} / E_{c}(t) .
\end{array}\right.
\end{aligned}
$$

\subsection{Probabilistic approach and evaluation of the structural effects}

As aforementioned, all strain peaks, the calculated loads and the corresponding time instants are stored in a list. However, lists are not easily readable when hundreds of rows are available for analysis and consequently, 
hundreds of events to analyse. Therefore, other formats are used to present the results, namely, histograms and correlation graphs, which are more suitable outputs for data reading and consulting.

With respect to the histograms, probability density functions can be used to fit the data in order to improve the analysis, with the main advantage of allowing the extrapolation of higher loads, In particular for the load histograms, extreme distribution functions are tested, namely, the Gumbel, Frechet and Weibull functions. The selection of these functions is justified by the fact that data sets of local peaks are in correspondence with independent traffic events (Montgomery, Runger 2003). In order to choose the best fitting function, a goodness-of-fit test is performed for each one, based on the chi-square distribution and the p-value to evaluate the null hypothesis " $\mathrm{H}_{0}$ : the type of the load histogram is a extreme function distribution" (Melchers 1999; Montgomery, Runger 2003). In advance, the best results were obtained with the Weibull distribution, Eqn (5), which might be explained by the two parameters, $\beta$ and $\delta$, that enable high flexibility for data fitting.

However, only strain peaks above the threshold value $Y_{0}$ are identifiable, which means that only loads above a certain value $x_{0}$ can be quantified. Hence, the Weibull distribution is not representative for traffic loads below $x_{0}$ (Eqn (5)), and consequently, values below $x_{0}$ should be disregarded and the remaining area delimited by the function should be normalised as presented in Eqn (6). Furthermore, different values of $x$ may be regarded as values to be exceeded with a probability $\alpha$ along a period $\tau$ (observation period), in agreement with Eqn (7) (Melchers 1999). This information can be very useful to create charts with different traffic load events related to different return periods, with the benefit of being based on real traffic conditions:

$$
\begin{array}{r}
f(x)=\frac{\beta}{\delta} \cdot\left(\frac{x}{\delta}\right)^{\beta-1} \cdot e^{\left[-\left(\frac{x}{\delta}\right)^{\beta}\right]} ; \\
x>0 ; \delta>0 ; \beta>0 \\
\bar{f}(x)= \begin{cases}0 & x \leq x_{0} \\
\frac{f(x)}{\int_{x 0}^{+\infty} f(x) d x} & x>x_{0} .\end{cases}
\end{array}
$$

Even so, characteristic values in correspondence to the structures' lifetime are required in order to enable a comparison with the design values within the framework of the structural safety assessment. The characteristic value related to the upper quantile 0.05 is normally used for design purposes, and the corresponding value estimated based on the monitoring data can be computed through Eqn (8).

$$
R_{p}(x)=\frac{\tau}{\alpha},\left\{\begin{array}{l}
t-\text { observation period } \\
\alpha=1-F(x)
\end{array}\right.
$$

$$
R_{p}=-\frac{T_{\text {lifetime }}}{\ln (1-\alpha)}, \quad \alpha=0.05
$$

An elastic behaviour of the structural materials is expected during the bridge operational life, even when they are subjected to heavy traffic load events. The permanent loads and the characteristic traffic loads previously calculated are both considered in the characteristic combination, according to Eurocode 0 (European Committee for Standardization 2002). Taking as reference a period equal to the structure lifetime, the bridge response under this load combination is appraised through FE analysis. At the end, the gathered results are compared with the limit values established by the bridge designer, in order to accurately assess the actual level of safety of the bridge.

The requirement of automatic calculation procedures, in order to avoid potential errors during the data handling and to improve the procedure efficiency, should be emphasised. Hence, the previous first three steps (Sections 3.1 to 3.3) are repeated in a while loop, in which a smaller database is handled. Finally, the procedure herein described was fully implemented in MENSUSMONITOR software, taking advantage of its features, namely real time acquisition, database storing/querying and filtering data.

\section{Results}

\subsection{Pinhão Bridge}

\subsubsection{Observation procedures}

For Pinhão Bridge, three strain gauges were selected. The first one, labelled as "SG-13B" in section P1E1, is located in the bottom flange of the mid-span transverse beam of the north span (Fig. 6). This gauge was selected taking into account the following: (i) the rehabilitation project revealed that the transverse beams are the most critical structural elements and (ii) this sensor is the one with the highest strain sensitivity for the same crossing load. An equivalent load histogram was calculated from the strain data collected by this gauge taking as reference the results from the load test. The shape of the influence line gauged for each identified vehicle was compared with the one collected for a single test truck so that real traffic data could be estimated. The factor that allowed this conversion was set based on results provided by the calibrated FE model, through which the correlation between the loading length and the strain evolution for different vehicles carrying the same load was evaluated. The other two selected sensors, labelled as "SG-1B" and "SG-5B", are installed in the upstream bottom chords of the trusses in the middle of the south and central spans, respectively (Fig. 6). Readings from these gauges were used to estimate the vehicles average speed. During the day of September $14^{\text {th }}, 2008$, the strain gauges were continuously interrogated with a sampling rate of $10 \mathrm{~Hz}$. 


\subsubsection{Traffic events identification}

The search for local peaks in the strain record of sensor "SG-13B" was performed over small observation periods, by splitting the 24-hour observation into subsets of $1 \mathrm{~h}$ each. Hence, temperature effects were removed from the records by simply offsetting them through a linear function, which is an acceptable procedure for a time window of one hour.

As a small example, Figure 5 shows the result for a period of approximately $50 \mathrm{~min}$, for which the identified local peaks (black circles) are stressed. The threshold value $Y_{0}$ was set to $4 \mu \varepsilon$, by taking into account the noise magnitude. This value can be considered low, regarding the resolution of the strain gauges, $(1 \mu \varepsilon)$.

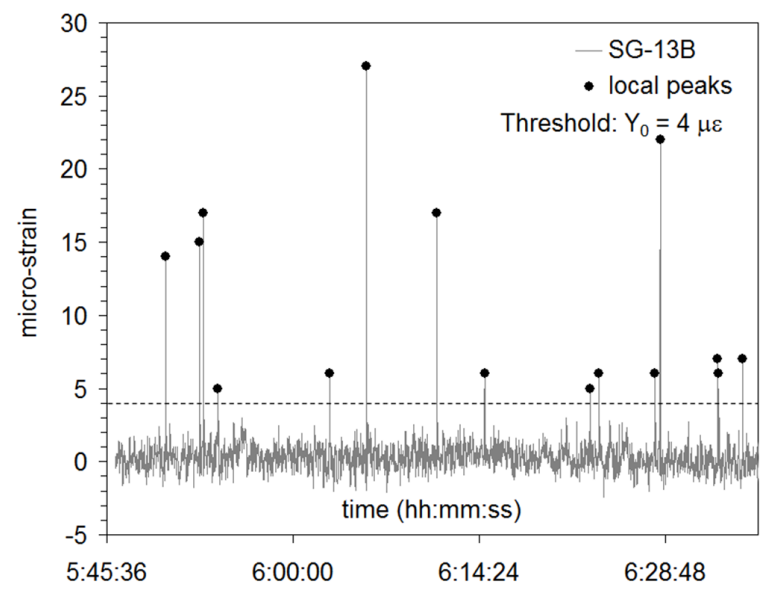

Fig. 5. Time series of the strain gauge "SG-13B"
Based on the records from sensors "SG-1B" and "SG-5B", an average speed of $37 \mathrm{~km} / \mathrm{h}$ was estimated with a standard deviation of $4 \mathrm{~km} / \mathrm{h}$. In fact, the average speed obtained for this case is in accordance with the speed limit established for the heavy vehicles travelling in the national roads in Portugal $(50 \mathrm{~km} / \mathrm{h})$.

\subsubsection{Load spectrum}

As aforementioned, Pinhão Bridge has a single lane along its deck, which leads to the traffic loads to be approximately centred with the longitudinal axis of the bridge. Consequently, torsion effects might be considered negligible. Hence, the sensitivity parameter, $k_{0}$, was set to 0.48 tons/ $\mu \varepsilon$ for the strain gauge "SG-13B (P1E1)". This value was obtained based on the results from the load test carried out after the rehabilitation works and it was confirmed by the FE analysis (Costa et al. 2008). On the other hand, the influence of the trucks' length used in the load tests was considered by a value of $\mathrm{k}_{1}$ equal to 1.23 . Taking into account Eqn (1) and the assigned threshold value $Y_{0}$, only traffic events loading more than 2 tons were identified. This load level suggests that the identified traffic events are related to medium/heavy vehicles, i.e. trucks.

The calculated loads were grouped into six load classes, as presented in Figure 7. The histogram exhibits an exponential shape and much of the traffic loads are lower than 8.25 tons. It is also worth mentioning that the load limit of 30 tons, established by the national road authority for the heavy vehicles crossing the bridge was never surpassed for the observation period.

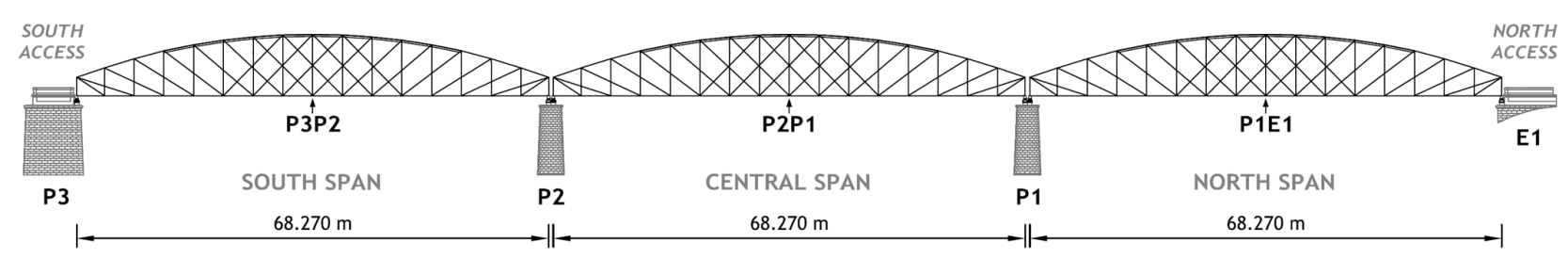

a) bridge elevation and location of the instrumented sections
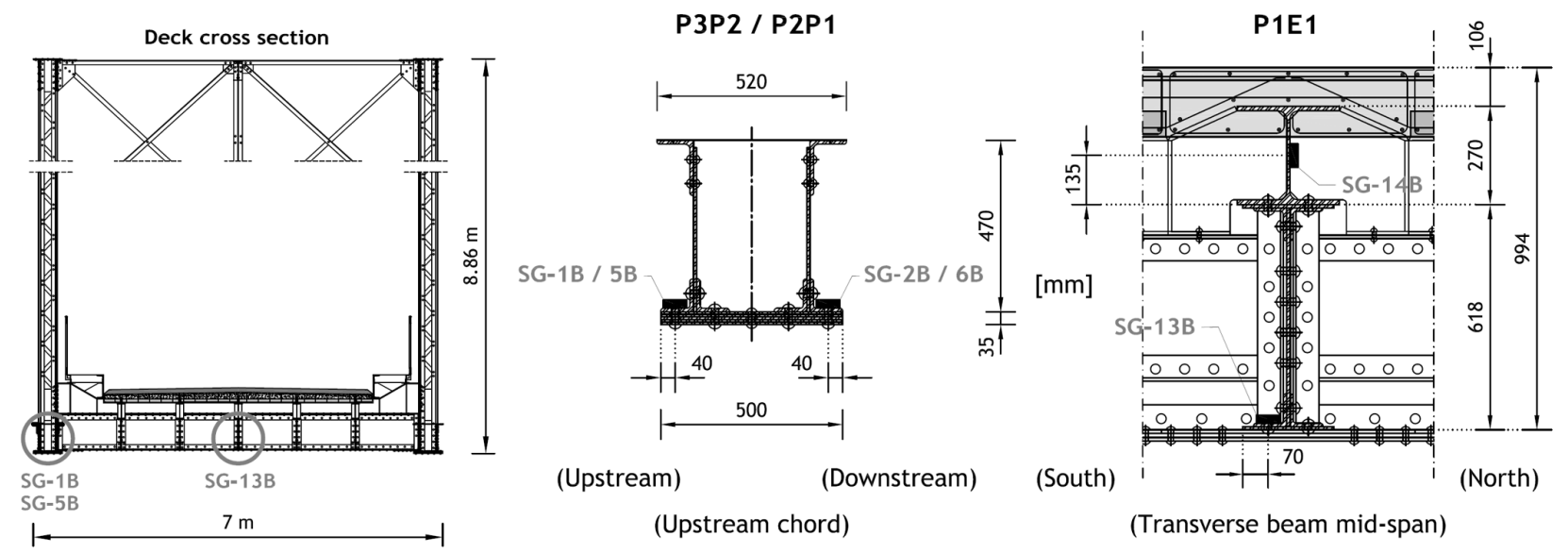

b) sensors' location in the mid-span cross sections

Fig. 6. Instrumentation plan of the Pinhão Bridge 


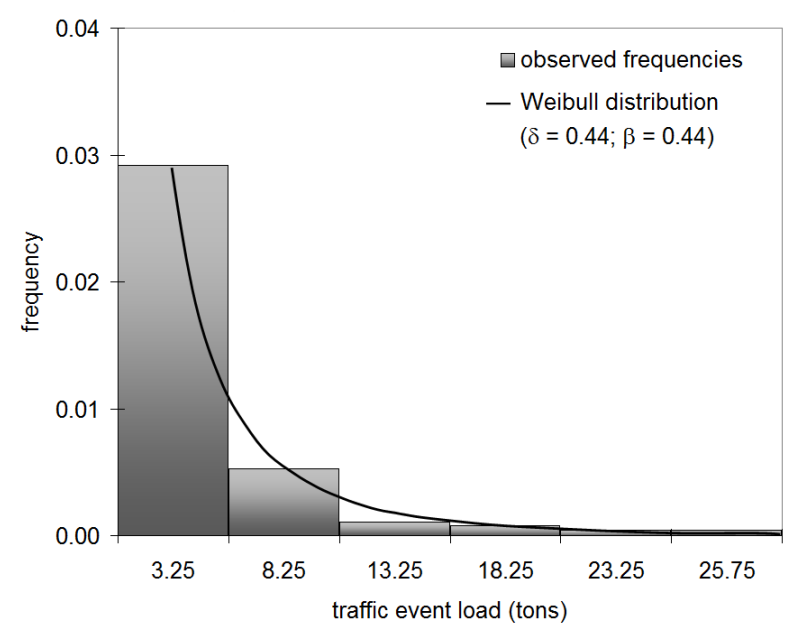

Fig. 7. Load distribution - Pinhão Bridge

\subsubsection{Probabilistic analysis and evaluation of structural effects}

The load histogram was fitted with the Weibull distribution (Eqn (6)) and the obtained result is overlapped in Figure 7 . The p-value for this adjustment is 0.37 , meaning that the null hypothesis " $\mathrm{H}_{0}$ : the form of the load distribution is Weibull" cannot be rejected for a significance level of 0.37 . This means that the probability of having a deviation from the expected load distribution because of pure chance is $37 \%$, which is statistically acceptable. Afterwards, higher loads were extracted from the fitted Weibull distribution, in order to estimate the characteristic traffic loads aiming at a structure lifetime of 30 years (the life-cycle assumed for the bridge rehabilitation). Based on FE analysis, this characteristic load and the permanent loads were considered together to evaluate the response of the bridge for a period equal to its lifetime.

From all of the numerical results available, the vertical displacements were selected for this study since this parameter is commonly used by bridge designers to establish alarm levels. This parameter holds the benefit of providing an overview of the structural behaviour, because it is easily correlated with the deformation level of the structure.

Therefore, and based on the 24-hour observation and for section P1E1, the first line of Table 1 presents the obtained vertical displacement, the characteristic load and the safety level, this last one set as the ratio between the project design value and the value calculated on the basis of the proposed methodology. As it can be depicted, the safety level computed for Pinhão Bridge is clearly lower than one. However, the interpretation of this result requires a throughout discussion. In fact, the strain measurements were collected for the period of the grape harvest season, during which the heavy daily traffic experiences an increase. This means that the data collected during the 24-hour observation period is well suited to characterize the average daily traffic in the grape harvest month. In other words, the return period related to the time window of observation is likely greater than one day. Assuming that the observation period corresponds to a return period of 28 days, the safety level almost reaches the unit value. Consequently, the estimated safety levels might be too conservative. In accordance with Table 1, Figure 8 plots different curves regarding the characteristic loads of the traffic events by assuming different return periods for the observation period.

\subsection{Lezíria Bridge}

\subsubsection{Observation procedures}

From all instrumented sections, two mid-span sections were selected. Figure 10 shows the location of these two cross sections, labelled as P1P2 and P2P3. In both, fibre optic strain gauges (SG) were installed at the bottom slab of the box girder, labelled as "SG-3B", which are aligned with the vertical and longitudinal symmetry axes of the bridge. Similar to Pinhão Bridge, during the 24-hour of May $14^{\text {th }}, 2009$, strain measurements were continuously

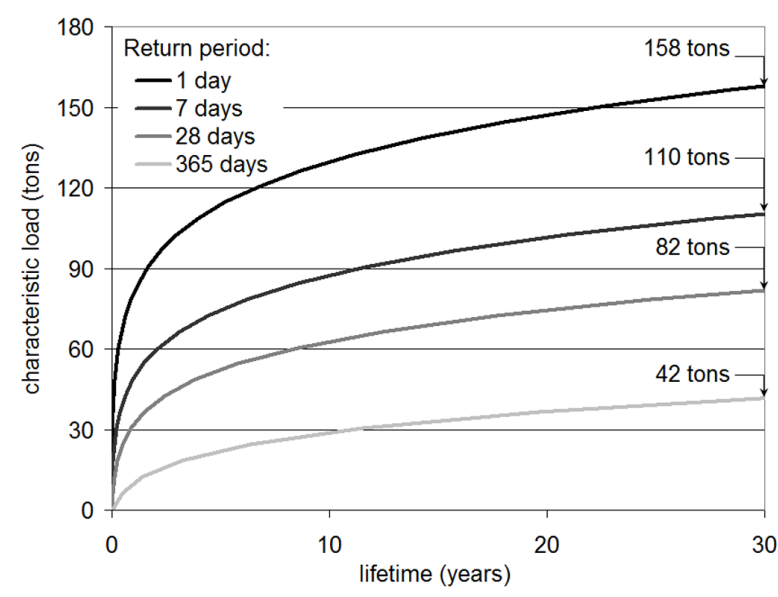

Fig. 8. Characteristic loads of the traffic events for different return periods - Pinhão Bridge

Table 1. Results of section P1E1 for a lifetime of 30 years

\begin{tabular}{|c|c|c|c|c|}
\hline \multirow{2}{*}{ Return period } & \multirow{2}{*}{$\begin{array}{l}\text { Characteristic load } \\
\text { (tons) }\end{array}$} & \multicolumn{2}{|c|}{ Vertical displacement (mm) } & \multirow{2}{*}{ Safety level } \\
\hline & & Project & Predicted & \\
\hline 1 day & 158 & \multirow{4}{*}{$48.7 *$} & 64.0 & 0.76 \\
\hline 7 days & 110 & & 55.1 & 0.88 \\
\hline 28 days & 82 & & 49.7 & 0.98 \\
\hline 365 days & 42 & & 42.2 & 1.15 \\
\hline
\end{tabular}

Note: *Value determined for the characteristic combination of actions, with a lower limit of L/800. 
acquired at a sampling rate of $50 \mathrm{~Hz}$.

\subsubsection{Traffic events identification}

Just as it was adopted for Pinhão Bridge, the $24 \mathrm{~h}$ observation period was split into subsets of $1 \mathrm{~h}$ each. Figure 9 presents data from a small period of observation, approximately 6 minutes, highlighting the identified local peaks. The threshold value, $Y_{0}$, was set to $3 \mu \varepsilon$, which can be regarded as sufficiently low value if compared with the precision of the strain gauge $(1 \mu \varepsilon)$. Based on the data collected by the two strain gauges, the average speed was found to be $85 \mathrm{~km} / \mathrm{h}$ and the standard deviation of $5 \mathrm{~km} / \mathrm{h}$. The estimated average speed is in accordance with the speed limit established for the heavy traffic in the Portuguese motorway roads, whose value is $90 \mathrm{~km} / \mathrm{h}$.

\subsubsection{Load spectrum}

Both the location of the fibre optic strain gauges at the symmetry vertical axis of the cross section (Fig. 10) and the outsized span length enable to consider negligible the tor-

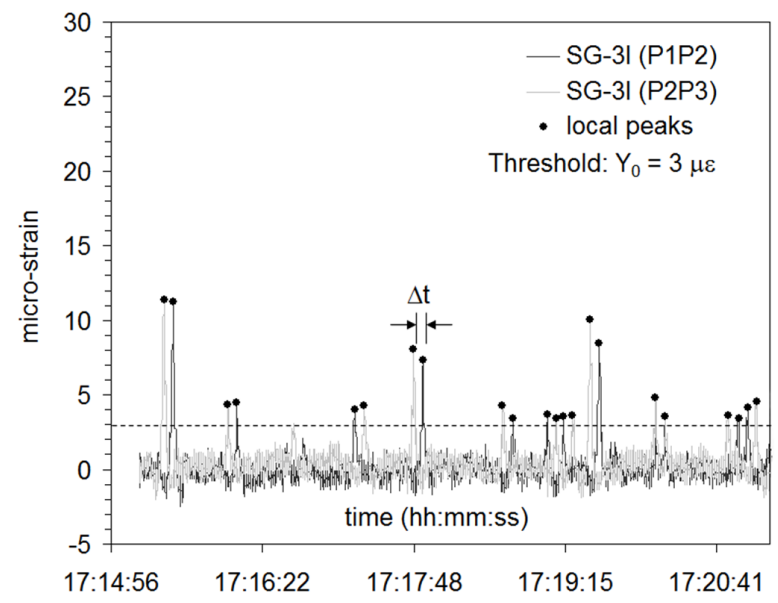

Fig. 9. Time series of the strain gauges "SG-3I" (P1P2) and "SG-3I" (P2P3) sion effects. Therefore, the sensitivity parameter, $k_{0}$, was set to 7.4 tons $/ \mu \varepsilon$ and 9.2 tons $/ \mu \varepsilon$ for strain gauges "SG3I (P1P2)" and "SG-3I (P2P3)", respectively (Fig. 10). These values were set based on the results from the load tests performed at the end of construction (Rodrigues et al. 2007) and properly validated by FE analysis (Sousa et al. 2014).

The influence of the trucks length used in the load tests was considered with a value of 1.26 for $k_{1}$. As far as the modulus of elasticity correction is concerned, the actual properties of the used concrete were taken into account and a value of 0.96 for parameter $k_{2}$ was set (TACE 2007).

Due to the value established for the threshold $Y_{0}$, only traffic events loading more than 18 tons were tracked, which are related to heavy vehicles, i.e. trucks. Afterwards, the identified traffic events were grouped into six load classes as presented in Figure 11.

On the contrary to results attained for Pinhão Bridge, the first load class exhibits a lower frequency if compared with the following two classes. In this case, a wider range of predominant traffic events exists with

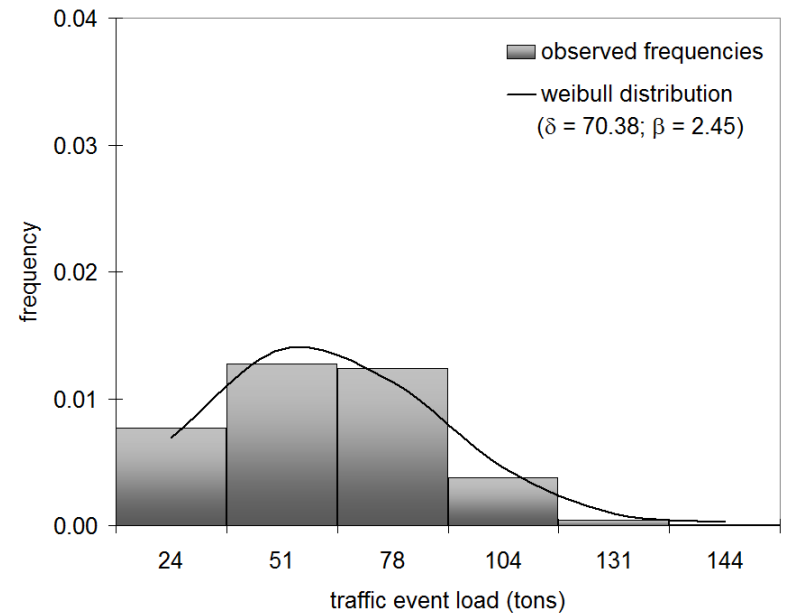

Fig. 11. Load distribution - Lezíria Bridge

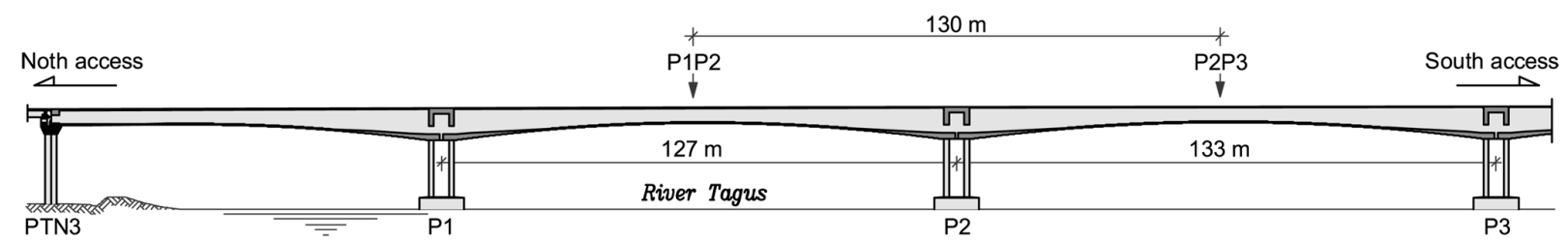

a) bridge elevation and location of the instrumented sections

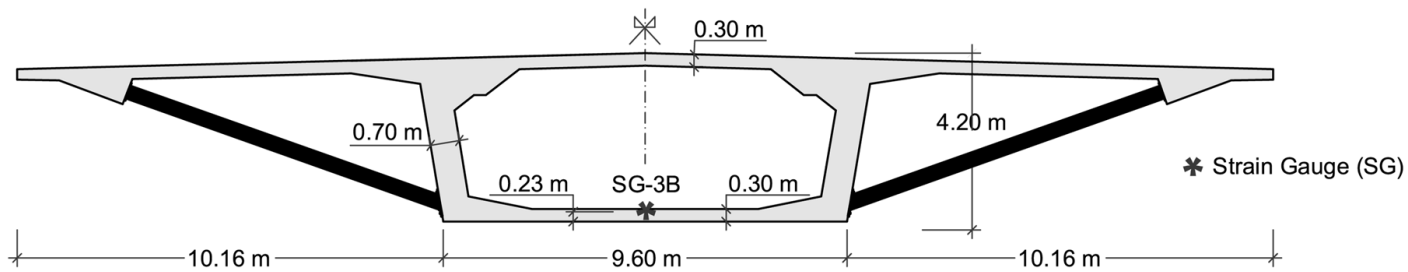

b) sensors' location in the mid-span cross sections

Fig. 10. Instrumentation plan of Lezíria Bridge 
prevailing loads ranging from 24 tons to 78 tons. Furthermore, traffic events loading more than 100 tons were also tracked, possibly due to the simultaneous crossing of two or more heavy trucks or even to the passage of special transportations, which is very likely to occur in motorways.

\subsubsection{Probabilistic analysis and evaluation of structural effects}

The Weibull distribution (Eqn (6)) was fitted to the load histogram (Fig. 11), with a p-value of 0.01. Although the fitting might not be so reliable as that obtained for Pinhão Bridge, it shows an acceptable agreement with the observed data and therefore, it is assumed that the Weibull distribution describe the actual loads related to the traffic events occurred in Lezíria Bridge. Aiming at a structure lifetime of 100 years, higher load levels were extrapolated in order to calculate the characteristic load for traffic events. The bridge behaviour was numerically evaluated for the combined action of the permanent loads with the computed characteristic traffic load. Similarly to what it was presented in Table 1, the first line of Table 2 shows the vertical displacement computed for section P2P3 in correspondence with the one day of observation period.

The results indicate that Lezíria Bridge exhibits a safety level of 1.23 , thus providing the bridge safe response even under extreme traffic loads. Even though the representativeness of the traffic observed during a $24 \mathrm{~h}$ period might be questionable (p-value of 0.01 ), the bridge safety is guaranteed. Figure 12 plots different characteristic load curves by assuming that the load histogram plotted in Figure 11 might also be representative of observation periods with a return period superior to one day. For this case, the load variability is not as high as for the case of Pinhão Bridge. Table 2 resumes the results obtained for the different return periods, and for all scenarios, the bridge safety is not compromised.

\subsection{Results comparison and discussion}

If the extrapolated characteristic loads obtained for both bridges are compared, it might be concluded that they are less variable for Lezíria Bridge. In fact, the shapes of the load histograms can explain these differences. While the load histogram of Lezíria Bridge is broadened with a wider range of predominant loads, approximately with the same significant contribution (Fig. 11), the one ob-

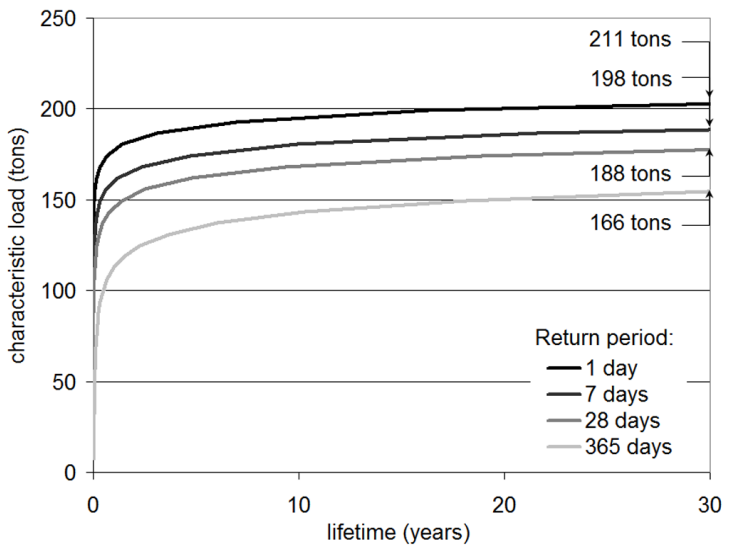

Fig. 12. Characteristic loads of the traffic events for different return periods - Lezíria Bridge

tained for Pinhão Bridge has a clear exponential shape (Fig. 7). Two main reasons can be pointed out to explain this fact. Firstly, smaller loads are measured in Pinhão Bridge (a minimum of 2 tons in opposition to the 18 tons in Lezíria Bridge), which leads to a higher frequency content in the first classes of the histogram. Secondly, as the number of exceptionally heavy traffic events detected increases, the right side of the load histogram becomes more stretched and therefore, also the end-right tail of the fitted Weibull distribution. The combined effect of these two issues enhances the exponential shape of the load histogram for the case of Pinhão Bridge. In fact, as aforementioned, the strain data collected from this bridge was performed during the grape harvest season, in which the number of heavy vehicles crossing the bridge is higher than for an average day of the year.

As far as the safety level is concerned, Lezíria Bridge may be clearly rated as a safe structure, while for Pinhão Bridge the evaluation is not so straightforward. Again, because the measurements collected from Pinhão Bridge were taken in the grape harvest season, during which the heavy traffic naturally experiences an increase, the computed characteristic loads are likely to be overestimated. Larger observation periods might solve this issue, something that has not been possible up to now. Hence, it is advised, if not mandatory, further studies with wider observation periods to evaluate with more accuracy the safety level of Pinhão Bridge when subjected to extreme traffic events.

Table 2. Results of section P2P3 for a lifetime of 100 years

\begin{tabular}{|c|c|c|c|c|}
\hline \multirow{2}{*}{ Return period } & \multirow{2}{*}{$\begin{array}{l}\text { Characteristic load } \\
\text { (tons) }\end{array}$} & \multicolumn{2}{|c|}{ Vertical displacement (mm) } & \multirow{2}{*}{ Safety leve } \\
\hline & & Project & Predicted & \\
\hline 1 day & 211 & \multirow{4}{*}{$55^{*}$} & 44.8 & 1.23 \\
\hline 7 days & 198 & & 43.9 & 1.25 \\
\hline 28 days & 188 & & 43.1 & 1.27 \\
\hline 365 days & 166 & & 41.7 & 1.32 \\
\hline
\end{tabular}

Note: *Value determined for the characteristic combination of actions, with a lower limit of L/1200. 
Furthermore, the different construction ages, the applied materials and the traffic requirements may also contribute to explain the different results achieved for these two case studies. In fact, the centenary Pinhão Bridge does not exhibit the same performance to traffic loads as the new Lezíria Bridge. In other words, different periods have to be considered for the expected lifetime of both bridges, which was in fact taken into consideration. Moreover, as it was previously expected and the results herein presented reveals, a more frequent checking procedure is required for Pinhão Bridge.

\section{Conclusions}

Based on strain measurements collected at high sampling rates, this work focuses on the assessment of traffic loads and their structural effects on road bridges. The results herein presented allow drawing some relevant conclusions, namely:

1) In order to extract information related to traffic events, data processing is computationally time-consuming, even more if large periods of observation are handled. The implementation of specific procedures devoted to data processing in dedicated software, such as MENSUSMONITOR, revealed efficiency, time saving and flexibility, with the plus of direct access to a database with the measurement.

2) The concept of influence line reveals to be an accurate strategy in order to optimize the sensors' selection for the characterization of loads due to traffic events. Moreover, measurements from strain gauges revealed to have a high correlation with traffic events.

3) The pre-treatment of sensor readings is crucial, namely the removal of environmental effects that must be done before any calculation. The adopted strategy of subsets of one hour observation each revealed to be efficient, namely because a linear function is enough to eliminate the trends on data.

4) For accurate predictions, data from a field calibration, i.e. a load test, is important in order to take into account the load length and the viscous-elastic behaviour of concrete.

5) The amplitude of the identified traffic load events for both bridges is the main difference on the attained results. In other words, for the same load, the strain sensitivity is higher for Pinhão Bridge, which is in accordance with the expectations given the different structural typologies and design requirements. Moreover, the results demonstrate the ability of instrumented metallic structures to identify smaller loads due to their higher sensitive to local effects and prone to experience higher deformations.

6) The obtained load histograms show different shapes for both bridges. While for Pinhão Bridge the diagram has an exponential shape, for Lezíria Bridge the lower frequency in the first load class sets the non-exponential shape. In other words, while for Pinhão Bridge the heavy traffic mainly comprises traffic loads weighing less than
8.25 tons, for Lezíria Bridge a larger spectrum of dominant loads is observed that ranges from 24 tons to 78 tons. The flexibility of Pinhão Bridge and the insertion of Lezíria Bridge in a motorway can explain these results.

7) Regarding the load histograms, the data fitting with the Weibull density function shows good agreement, namely for the case of Pinhão Bridge with a p-value of 0.37 .

8) As regards the structural response and focussing on the lifetime of both bridges the expected loads for traffic events, based on the Weibull distribution, do not endanger the safety of Lezíria Bridge, whereas with respect to Pinhão Bridge the conclusions are not so straightforward. Nevertheless, the estimated characteristic loads for Pinhão Bridge can be overestimated and the safety level under evaluated because the used data was collected during the grape harvest season, a period for which an increase on the heavy traffic is expected. In spite of this, if the obtained load histogram is taken as representative of the entire grape harvest month, the safety level reaches almost the unit.

9) Due to the fact that the observation period used for Pinhão Bridge matched the grape harvest season and the low p-value attained for the case of Lezíria Bridge, the collection of longer observation periods for both bridges is recommended.

10) These kind of tools can be useful for structural safety analysis and heavy load events counting only. Strain inducing load events are detected, which means that the readings do not enable direct vehicles counting.

11) Finally, these results show potential to support the management of road bridges, namely, for restrictive actions to the traffic, viability studies and/or rehabilitation of structures.

\section{Acknowledgements}

The authors gratefully acknowledge the financial support provided by the Portuguese Foundation for Science and Technology (FCT-MCES) to the first and second authors through the $\mathrm{PhD}$ grants $\mathrm{SFRH} / \mathrm{BD} / 29125 / 2006$ and $\mathrm{SFRH} / \mathrm{BD} / 13138 / 2003$, respectively. The authors also thank the bridges owners BRISA - Auto-Estradas de Portugal S.A. and EP - Estradas de Portugal, E.P.E. for their assistance and cooperation.

\section{References}

Bergmeister, K.; Santa, U. 2001. Global monitoring concepts for bridges, Structural Concrete 2(1): 29-39. http://dx.doi.org/10.1680/stco.2001.2.1.29

Chang, S.-P.; Yee, J.; Lee, J. 2009. Necessity of the bridge health monitoring system to mitigate natural and manmade disasters, Structure \& Infrastructure Engineering: Maintenance, Management, Life-Cycle Design and Performance 5(3): 173-197. http://dx.doi.org/10.1080/15732470601130378

Costa, B. J. A.; Faria, R.; Figueiras, J. 2008. Instrumentation and observation of the Pinhão Bridge behavior during the load tests. Porto LABEST, Faculty of Engineering of the University of Porto. 
Costa, B. J. A.; Félix, C.; Figueiras, J. A. 2009. Design and installation of an electric based monitoring system applied to a centenary metallic bridge, in ASCP'09- $1^{\circ}$ Congresso de Segurança e Conservação de Pontes, 1-3 July 2009, Lisbon, Portugal.

Cremona, C. 2001. Optimal extrapolation of traffic load effects, Structural Safety 23(1): 31-46. http://dx.doi.org/10.1016/S0167-4730(00)00024-2

European Committee for Standardization 2002. Designers' guide to EN 1990 Eurocode basis of structural design. London: Thomas Telford.

Getachew, A.; Obrien, E. 2007. Simplified site-specific traffic load models for bridge assessment, Structure \& Infrastructure Engineering: Maintenance, Management, LifeCycle Design \& Performance 3(4): 303-311. http://dx.doi.org/10.1080/15732470500424245

Jowell, R. 2001. Entre-Os-Rios Bridge tragedy. City University London, UK: European Social Survey (ESS) [online], [cited 20 February 2011]. Available from Internet: http://www.europeansocialsurvey.org/index. php?view $=$ details \&id $=6231 \% 3$ Aentre-os-ris-bridgetragedy\&option $=$ com eventlist\&Itemid $=326$

Karoumi, R.; Wiberg, J.; Liljencrantz, A. 2005. Monitoring traffic loads and dynamic effects using an instrumented railway bridge, Engineering Structures 27(12): 1813-1819. http://dx.doi.org/10.1016/j.engstruct.2005.04.022

Liljencrantz, A.; Karoumi, R. 2009. Twim: A MATLAB toolbox for real-time evaluation and monitoring of traffic loads on railway bridges, Structure and Infrastructure Engineering: Maintenance, Management, Life-Cycle Design and Performance 5(5): 407-417. http://dx.doi.org/10.1080/15732470701478370

Liljencrantz, A.; Karoumi, R.; Olofsson, P. 2007. Implementing bridge weigh-in-motion for railway traffic, Computers \& Structures 85(1-2): 80-88. http://dx.doi.org/10.1016/j.compstruc.2006.08.056

Melchers, R. E. 1999. Structural reliability analysis and prediction. Chichester: John Wiley \& Sons.

Montgomery, D. C.; Runger, G. C. 2003. Applied statistics and probability for engineers. $3^{\text {rd }}$ ed. New-York: John Wiley.
Moses, F. 1979. Weigh-in-motion system using instrumented bridges, Transportation Engineering Journal ASCE 105(3): 233-249.

Rodrigues, C.; Sousa, H.; Félix, C.; Figueiras, J. 2007. Travessia do Tejo no Carregado, no Sublanço A1 / Benavente, da A10 - Auto-Estrada Bucelas / Carregado / IC3 - ensaios de recepção. Porto: Labest, Faculty Of Engineering Of The University Of Porto.

Savitzky, A. G. M. J. E. 1964. Smoothing and differentiation of data by simplified least squares procedures, Analytical Chemistry 36(8): 1627-1639. http://dx.doi.org/10.1021/ac60214a047

Sousa, H.; Bento, J.; Figueiras, J. 2014. Assessment and management of concrete bridges supported by monitoring data-based finite-element modeling, Journal of Bridge Engineering 19(6): 05014002. http://dx.doi.org/10.1061/(ASCE)BE.1943-5592.0000604

Sousa, H.; Dimande, A.; Rodrigues, C.; Henriques, A.; Figueiras, J. 2009. MENSUSMONITOR - Software for the treatment and interpretation of experimental results, in RPEE Revista Portuguesa de Engenharia de Estruturas. Serie 2.

Sousa, H.; Félix, C.; Bento, J.; Figueiras, J. 2011. Design and implementation of a monitoring system applied to a longspan prestressed concrete bridge, Structural Concrete 12(2): 82-93. http://dx.doi.org/10.1002/suco.201000014

Sousa, H.; Henriques, A.; Figueiras, J. 2006. Tratamento de resultados experimentais em estruturas com base em filtros de alisamento de Savitzky-Golay, in 4 Jornadas Portuguesas de Engenharia de Estruturas, JPEE2006, LNEC Laboratório Nacional de Engenharia Civil, 13-16 December 2006, Lisbon, Portugal.

TACE. 2007. Construção da Travessia do Tejo no Carregado Sublanço A1/Benavente, da A10 Auto-Estrada Buce-las/ Carregado/IC3. Plano de Qualidade.

Van Der Auweraer, H.; Peeters, B. 2003. International research projects on structural health monitoring: an overview, Structural Health Monitoring 2(4): 341-358. http://dx.doi.org/10.1177/147592103039836

Helder SOUSA. Dr, Postdoctoral Researcher in the Department of Civil \& Environmental Engineering at the University of Surrey, UK, since 2013. Received is PhD in 2012 at the Faculdade de Engenharia da Universidade do Porto, Portugal. Participation in several research projects (since 2003) in the field of bridge health monitoring (SHM), namely, project design, field implementation and assessment of structural safety based on data-based engineering techniques. With focus on bridge management based on monitoring data, his research interests include optimisation and design of monitoring systems, pattern recognition, software packages development and optimised FE models devoted to SHM.

Bruno J. A. COSTA. Postdoctoral Researcher in the Department of Civil Engineering at the Faculty of Engineering of the University of Porto (FEUP) since 2013. He completed his 5-years Bachelor's degree of Civil Engineering in 2000 at the University of Beira Interior and received his post-graduation in Civil Engineering Structures at the Faculty of Engineering of the University of Porto in 2003. During his studies regarding the PhD obtained at FEUP on Structural Identification of Old Steel Bridges he was engaged in several SHM and field testing projects. His research interests include non-destructive testing and evaluation of structures, structural health monitoring, analytical simulation and characterisation, structural safety and dynamics, rehabilitation and strengthening of bridges.

António Abel HENRIQUES. Dr, Associate Professor in the Civil Engineering Department, Faculty of Engineering University of Porto since 2010. Member of the Research Unit LABEST - Laboratory for the Concrete Technology and the Structural Behaviour (since 2003). Graduate in 1987 and $\mathrm{PhD}$ in Civil Engineering in 1998 by the University of Porto. Participation in several research projects since 1991 in the field of structural concrete, analysis and design of concrete structures, structural health monitoring and evaluation of structural integrity and assessment of structural safety. Research interest in the field of advanced techniques for the structural reliability analysis, application of advanced numerical models for the structural safety assessment, numerical modelling of concrete structures strengthened with advanced materials. 
João BENTO. Dr. is the CEO of Efacec (Portugal's leading power systems industrial provider) the VP of the Portuguese Engineering Academy and the President of COTEC (Portuguese Association for Corporate Innovation). He is a Civil Eng. with an MSc in Structures (IST, Lisbon), a PhD in Civil Eng., (Imperial College, London), and an Agregação in Intelligent Systems (IST). Between 2000 and 2011 he was an Executive Director for Brisa Auto-Estradas de Portugal, where he had initially taken responsibility for the operational restructuring of the company and later became responsible for all business development activities, including diversification and internationalisation. Previously he served in the Board of various other companies, such as EDP, CCR (Brazil), Adamastor Capital, Brisatel and Logiser. He is Honorary (and Past) President of the European Association of Tolled Motorways (2006-07) and was Member of the BoD of International Bridge, Tunnel and Turnpike Association (2008-11). A former Full Professor at IST, he kept a regular involvement as Visiting Academic, having supervised $11 \mathrm{PhD}$ Theses and $15 \mathrm{MSc}$ Theses. He has authored or coauthored more than 160 scientific papers, books or book chapters, mostly in the areas of Computer-Aided Engineering and Design Support Systems.

Joaquim A. FIGUEIRAS. Full Professor in the Civil Engineering Department, Faculty of Engineering University of Porto since 1993. Scientific Coordinator of the Research Unit LABEST - Laboratory for the Concrete Technology and the Structural Behaviour (2003-2011). Graduate in Civil Engineering by the University of Porto (1973), PhD by the University of Wales, Swansea, U.K. (1983), Aggregation degree in Structures of Civil Engineering by University of Porto (1993). Responsible for several R\&D projects in the field of structural materials technology, bridge monitoring, and bridge examination and conservation condition. Research interest in the field of nonlinear analysis and safety verification of concrete structures, condition assessment of existing structures and structural health monitoring. 